\title{
Resonance Raman studies of Rieske-type proteins
}

\author{
Debasish Kuila ${ }^{\text {a,1 }}$, Jon R. Schoonover a,2, R. Brian Dyer ${ }^{\text {a,3 }}$, Christopher J. Batie ${ }^{\text {b,4 }}$, \\ David P. Ballou ${ }^{\mathrm{b}}$, James A. Fee ${ }^{\mathrm{a}}$ and William H. Woodruff ${ }^{\mathrm{a}}$ \\ ${ }^{a}$ Biochemistry and Spectroscopy Group, Isotope and Structural Chemistry Division, Los Alamos National Laboratory, Los Alamos, \\ NM (USA) and ${ }^{b}$ Department of Biological Chemistry, The University of Michigan, Ann Arbor, MI (USA)
}

(Received 18 May 1992)

Key words: Iron-sulfur protein; Iron-sulfur cluster; Resonance Raman spectroscopy; Rieske-type cluster

\begin{abstract}
Resonance Raman (RR) spectra are reported for the [2Fe-2S] Rieske protein from Thermus thermophilus (TRP) and phthalate dioxygenase from Pseudomonas cepacia (PDO) as a function of $\mathrm{pH}$ and excitation wavelength. Depolarization ratio measurements are presented for the RR spectra of spinach ferredoxin (SFD), TRP, and PDO at $74 \mathrm{~K}$. By comparison with previously published RR spectra of SFD, we suggest reasonable assignments for the spectra of TRP and PDO. The spectra of PDO exhibit virtually no $\mathrm{pH}$ dependence, while significant changes are observed in TRP spectra upon raising the $\mathrm{pH}$ from 7.3 to 10.1. One band near $270 \mathrm{~cm}^{-1}$, which consists of components at $266 \mathrm{~cm}^{-1}$ and $274 \mathrm{~cm}^{-1}$, is attributed to $\mathrm{Fe}(\mathrm{III})$-N(His) stretching motions. We suggest that these two components arise from conformers having a protonated-hydrogen-bonded imidazole $\left(266 \mathrm{~cm}^{-1}\right)$ and deprotonated-hydrogen-bonded imidazolate $\left(274 \mathrm{~cm}^{-1}\right)$ coordinated to the $\mathrm{Fe} / \mathrm{S}$ cluster and that the relative populations of the two species are pH-dependent; a simple structural model is proposed to account for this behavior in the respiratory-type Rieske proteins. In addition, we have identified RR peaks associated with the bridging and terminal sulfur atoms of the Fe-S-N cluster. The RR excitation profiles of peaks associated with these atoms are indistinguishable from each other in TRP (pH 7.3) and PDO and differ greatly from those of [2Fe-2S] ferredoxins. The profiles are bimodal with maxima near $490 \mathrm{~nm}$ and $>$ approx. $550 \mathrm{~nm}$. By contrast, bands associated with the Fe-N stretch show a somewhat different enhancement profile. Upon reduction, RR peaks assigned to $\mathrm{Fe}-\mathrm{N}$ vibrations are no longer observed, with the resulting spectrum being remarkably similar to that reported for reduced adrenodoxin. This indicates that only modes associated with $\mathrm{Fe}-\mathrm{S}$ bonds are observed and supports the idea that the reducing electron resides on the iron atom coordinated to the two histidine residues. Taken as a whole, the data are consistent with an $\mathrm{S}_{2}^{\mathrm{t}} \mathrm{FeS}{ }_{2}^{\mathrm{b}} \mathrm{Fe}[\mathrm{N}(\mathrm{His})]_{2}^{\mathrm{t}}$ structure for the Rieske-type cluster.
\end{abstract}

\section{Introduction}

Proteins containing two $\mathrm{Fe}$ atoms and two inorganic $S$ atoms in a [2Fe-2S] cluster are widely observed in nature, where they serve primarily as electron transfer agents [1,2]. At least four different classes of proteins that bind this cluster are known to exist. The first is the ferredoxins, which possess a nominally constant set of spectral properties and for which the $\mathrm{Fe} / \mathrm{S}$ cluster is

Correspondence to: J.A. Fee, INC-14, MS C-345, LANL, Los Alamos, NM 87545, USA.

${ }^{1}$ Present address: Department of Physiology and Biophysics, Albert Einstein College of Medicine, Bronx, NY 10461, USA.

2 Present address: Department of Chemistry, University of North Carolina, Chapel Hill, NC 27599, USA.

${ }^{3}$ Present address: Chemical and Laser Science Group, Los Alamos National Laboratory, Los Alamos, NM 87545, USA.

${ }^{4}$ Present address: Department of Biochemistry and Molecular Biology, Lousiana State University Medical Center, New Orleans, LA 70112, USA. known to be coordinated to the protein by four cysteinyl $S$ atoms [1-5]. Recently, the three-dimensional structures of ferredoxins from Spirulina platensis [4] and Anabaena [5] have been determined. Each contains a [2Fe-2S] cluster in which each $\mathrm{Fe}$ atom is coordinated by the two bridging sulfur atoms and by two cysteinyl sulfur atoms, i. e., $\left[\mathrm{Fe}_{2} \mathrm{~S}_{2}^{\mathrm{b}}\right] \mathrm{S}^{\mathrm{t}}(\mathrm{Cys})_{4}$ unit $\left(S^{b}=\right.$ bridging, $S^{\mathfrak{t}}=$ terminal), and the coordination geometry at each $\mathrm{Fe}$ is roughly tetrahedral. Ferredoxins from other sources as well as synthetic analogs containing the $[2 \mathrm{Fe}-2 \mathrm{~S}]$ cluster have been widely characterized (cf. Refs. 1-3, 6, 7). The second class includes proteins such as adrenodoxin and putidaredoxin that have spectral properties distinct from the ferredoxins, but which nevertheless probably sequester the $\mathrm{Fe} / \mathrm{S}$ cluster with cysteine residues $[8,9]$; their three-dimensional structures are not known. The third group is a new class of [2Fe-2S] containing proteins, discovered by Flint and Emptage [10]. These proteins have not yet been well characterized, but it has been suggested that non-sulfur atoms are coordinated to the [2Fe-2S] cluster. Finally, 
there are the so-called Rieske-type proteins (cf. Refs. 11-18 and references therein). Specific systems that have contributed to our knowledge of this class include the Rieske proteins from Thermus thermophilus (TRP) and Rhodobacter capsulatus, the mitochondrial Rieske protein, and phthalate dioxygenase (PDO) from Pseudomonas cepacia, as well as others.

The spectral and redox properties of Rieske-type centers are quite distinct from those of ferredoxins. Some notable differences include an average EPR $g$ value of 1.91 compared with 1.96 for the ferredoxins, a red-shifted, visible absorption with maximum absorptivity about 0.67 that of the ferredoxins, and very different circular dichroic spectra (cf. Ref. 11). The mid-point potentials of Rieske-type proteins are higher than ferredoxins and vary considerably within the group. The potentials of the respiratory-type proteins are unusually high, up to $350 \mathrm{mV}$, and linked to an ionization in the oxidized protein having a $\mathrm{p} K_{\mathrm{a}}$ between 8 and 9 , while those of Rieske-type dioxygenases are typically less than $-100 \mathrm{mV}$ and independent of $\mathrm{pH}$. Ferredoxins have the lowest midpoint potentials $(\sim-400 \mathrm{mV})$, while putidaredoxin has a midpoint potential near $-250 \mathrm{mV}$ (cf. Refs. 11, 16 and references therein).

A combination of compositional and ENDOR studies of TRP, PDO and the cytochrome $b c_{1}$ complex from $R$. capsulatus and other organisms have shown that the $[2 \mathrm{Fe}-2 \mathrm{~S}]$ cluster in these proteins is coordinated by two histidines [13-15,18]. Preliminary RR results from our laboratories [17] suggested that the [2Fe-2S] clusters in TRP and PDO have $\mathrm{C}_{2 v}$ symmetry, while Mössbauer studies of TRP [18] suggested that one Fe-atom of the cluster was coordinated to $4 \mathrm{~S}$ atoms, in both oxidized and reduced forms. These observations have led to a structural model in which 2 Cys coordinate one $\mathrm{Fe}$ while 2 His coordinate the other $\mathrm{Fe}, \mathrm{S}_{2}^{\mathrm{t}} \mathrm{FeS}{ }_{2}^{\mathrm{b}} \mathrm{Fe}[\mathrm{N}(\mathrm{His})]_{2}^{\mathrm{t}}$; the model has been used to rationalize the above noted differences between ferredoxins and Rieske-type proteins (cf. Ref. 11).

Within this class of proteins there are significant differences, beginning with the nature of the protein moieties. TRP $\left(M_{\mathrm{r}} \approx 20000\right)$ appears to contain two identical [2Fe-2S] clusters in contrast to one [2Fe-2S] cluster in mitochondrial Rieske protein $\left(M_{\mathrm{r}} \approx 24000\right)$ and phthalate dioxygenase $\left(M_{\mathrm{r}} \approx 48000\right)$. Moreover, while the $\mathrm{Fe} / \mathrm{S}$ cluster appears to be coordinated similarly in all cases, significant differences in spectral properties and chemical behavior indicate that the immediate environment of the cluster varies among the different proteins. Since RR spectroscopy has been extensively applied to [2Fe-2S]-containing ferredoxins (cf. Ref. 19 and references therein), we are utilizing this method to understand the similarities and differences between the $\mathrm{Fe} / \mathrm{S} / \mathrm{N}$ clusters of TRP and PDO and the $\mathrm{Fe} / \mathrm{S} / \mathrm{S}$ cluster of SFD. We present RR spectra of these systems in different states of protona- tion and reduction and as a function of excitation wavelength. The results are discussed in relation to previously reported data for various [2Fe-2S] proteins [19-25] and synthetic analogues [26,27].

\section{Materials and Methods}

The Rieske protein from Thermus thermophilus (TRP) was isolated by the method of Fee et al. with $A_{460} / A_{280}=0.22$ [18]. The spinach ferredoxin (SFD) was purified by the procedure of Petering and Palmer [28]. The purity index of SFD was $>0.47$ for all samples. The phthalate dioxygenase protein (PDO) from Pseudomonas cepacia was purified by the method of Batie et al. [29] with $A_{460} / A_{280}=0.07$ for the isolated protein. Samples of SFD, TRP and PDO were prepared in Hepes at $\mathrm{pH}$ 7.3. The high-pH (pH 10.1) sample of TRP was buffered with CAPS ((3-cyclohexylamino)-1-propanesulfonic acid). All the samples used for RR spectroscopy were concentrated to an optical absorbance of about 1 per $\mathrm{mm}$ at $460 \mathrm{~nm}$ (about $1 \mathrm{mM}$ in $\mathrm{Fe} / \mathrm{S}$ ). In all cases, samples were washed using an Amicon concentrator with several cycles in the desired buffer, and the final concentration was achieved by evaporation using a gentle flow of dry nitrogen. Highly luminesent RR samples were treated with charcoal to remove impurities, after which they were passed through a G-25 column equilibrated with the appropriate buffer. Samples used in the depolarization ratio measurements were concentrated to $>2 \mathrm{mM}$ and diluted to $1 \mathrm{mM}$ with ethylene glycol to give a $50 \%$ ethylene glycol solution; when frozen, these samples formed an optically clear glass. For the reduced protein studies, TRP and PDO were exposed to excess dithionite and immediately frozen for the RR measurements. Upon completion of the experiments, excess dithionite was removed using ultrafiltration and the purity index of the re-oxidized protein was checked, as were the samples of oxidized proteins.

RR spectra were obtained using a SPEX 1403 spectrometer equipped with a cooled RCA 31034 photomultiplier tube. Data acquisition was controlled by a MacIntosh II (Apple Computer). Laser excitation was provided by either a Spectra Physics 171-19 $\mathrm{Ar}^{+}$or $171-01 \mathrm{Kr}^{+}$laser. A Coherent model 599 dye laser with Rhodamine 590 pumped by the $\mathrm{Ar}^{+}$laser was also used. Spectra were obtained using a scan rate of 1 $\mathrm{cm}^{-1} \mathrm{~s}^{-1}$ and a spectral resolution of $4 \mathrm{~cm}^{-1}$. Raman scattering was collected in a $135^{\circ}$ backscattering geometry off the surface of the frozen solution at nominal liquid nitrogen temperature $(74 \mathrm{~K}, 0.82 \mathrm{~atm})$. Laser power for all spectra was between 50 and $100 \mathrm{~mW}$ at the cryo window. Unless indicated otherwise, the spectra were not subjected to smoothing routines. All RR intensities were measured relative to the ice peak at $230 \mathrm{~cm}^{-1}$. 


\section{Results and Discussion}

\section{Raman spectra}

The resonance Raman (RR) spectra of the oxidized forms of SFD at $\mathrm{pH} 7.3$, TRP at $\mathrm{pH} 7.3$ and 10.1, and PDO at $\mathrm{pH} 7.3$ are presented in Fig. 1. The principal RR frequencies of these systems at various excitation wavelengths are compared in Table I. With excitation into the strong visible absorption bands, which by comparison to other $\mathrm{Fe}-\mathrm{S}$ proteins are presumed to be associated with $\mathrm{S} \Rightarrow \mathrm{Fe}$ charge-transfer transitions, the $\mathrm{RR}$ spectra between 100 and $450 \mathrm{~cm}^{-1}$ are expected to be dominated by $\mathrm{Fe}-\mathrm{S}$ vibrational modes. With the Rieske proteins, one might also expect to observe $\mathrm{Fe}-\mathrm{N}$ vibrational modes. The spectrum of SFD is nearly identical to the spectrum of ferredoxin from Spirulina platensis which has a known crystal structure [23,25]; this structure is thus useful in interpreting the data for SFD *. SFD has been extensively studied by RR spectroscopy and assignments have been made using comparisons with [2Fe-2S] model complexes, isotopic substitution, excitation profiles and normal coordinate analysis [19-27].

The assignments in ferredoxins and by inference the

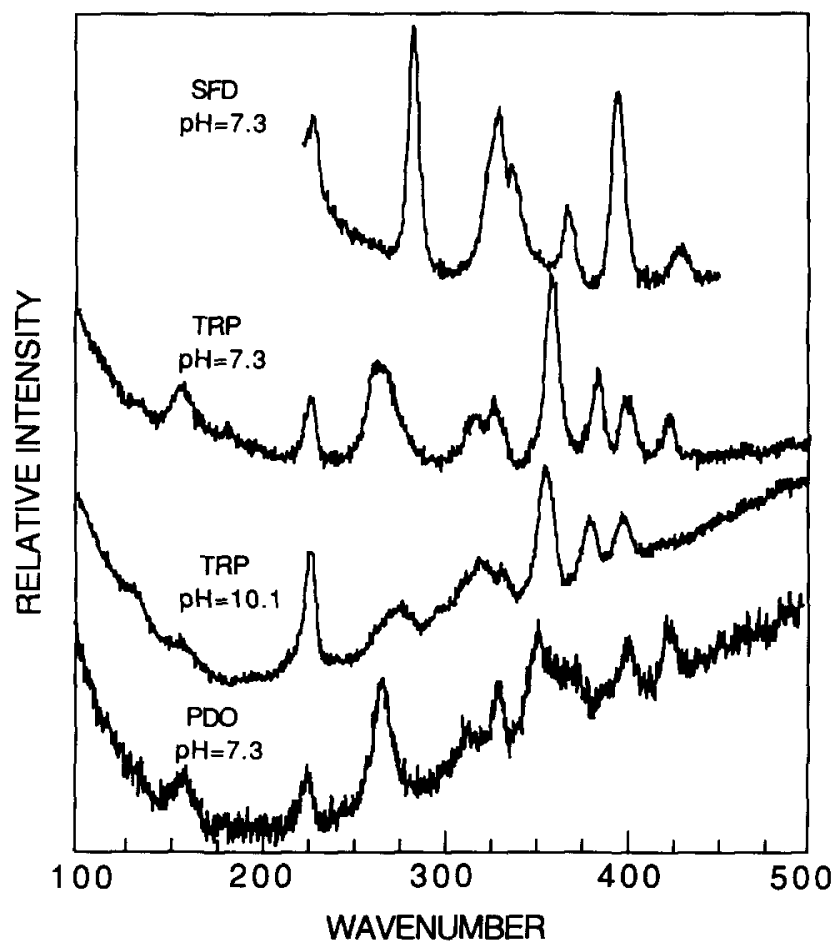

Fig. 1. Resonance Raman (RR) spectra between 100 and $450 \mathrm{~cm}^{-1}$ of oxidized samples of SFD at pH 7.3, TRP at pH 7.3, TRP at $\mathrm{pH}$ 10.1 and $\mathrm{PDO}$ at $\mathrm{pH} 7.3$. Excitation wavelengths were $457.9 \mathrm{~nm}$ for SFD, $568.3 \mathrm{~nm}$ for PDO and TRP at $\mathrm{pH} 7.3$ and $488.0 \mathrm{~nm}$ for TRP at $\mathrm{pH} 10.1$. The spectra were obtained at $74 \mathrm{~K}$ in a $135^{\circ}$ backscattering geometry with laser power between 50 and $100 \mathrm{~mW}$ at the cryowindow. The scan rate was $1 \mathrm{~cm}^{-1} \mathrm{~s}^{-1}$ with a spectral resolution of $4 \mathrm{~cm}^{-1}$. The optical absorbance for the protein samples was $>1 / \mathrm{mm}$ at $460 \mathrm{~nm}$ (i.e., concentration $>1 \mathrm{mM}$ ).
TABLE I

Comparison of resonance Raman peaks $\left(250-450 \mathrm{~cm}^{-1}\right)$ for Thermus Rieske protein (TRP), Pseudomonas phthalate dioxygenase (PDO), and ferredoxins from Spinacea aleracea (SFD) and Porphyra umbilicalis (PUF)

\begin{tabular}{|c|c|c|c|c|c|}
\hline \multirow[t]{2}{*}{ Mode $^{b}$} & \multicolumn{2}{|l|}{ TRP } & \multirow[t]{2}{*}{$\mathrm{PDO}^{\mathrm{a}}$} & \multirow[t]{2}{*}{$\mathrm{SFD}^{\mathrm{a}}$} & \multirow[t]{2}{*}{ PUF $^{a}$} \\
\hline & $\mathrm{pH} 7.3$ & $\mathrm{pH} 10.1$ & & & \\
\hline $\mathrm{Fe}-\mathrm{N}^{t}$ & 266 & $266 \mathrm{sh}^{\mathrm{i}}$ & - & - & \\
\hline $\mathrm{Fe}-\mathrm{N}^{\mathrm{t}}$ & $274 \mathrm{w}, \mathrm{sh}$ & 274 & - & - & \\
\hline $\mathrm{Fe}-\mathrm{S}^{\mathrm{t}}$ & - & - & - & 283 & 282 \\
\hline $\mathrm{Fe}-\mathrm{N}^{t}$ & - & 300 & - & - & - \\
\hline $\mathrm{Fe}-\mathrm{S}^{\mathrm{t}}$ & 322 & 322 & 315 & - & - \\
\hline $\mathrm{Fe}-\mathrm{S}^{\mathrm{b}}$ & 330 & 330 & 334 & 329 & 329 \\
\hline $\mathrm{Fe}-\mathrm{S}^{\mathrm{t}}$ & - & - & - & 336 & 339 \\
\hline $\mathrm{Fe}-\mathrm{S}^{\mathrm{t}}$ & 360 & 357 & 354 & $350 w$ & 357 \\
\hline $\mathrm{Fe}-\mathrm{S}^{\mathrm{t}}$ & - & - & 372 & - & - \\
\hline $\mathrm{Fe}-\mathrm{S}^{\mathrm{b}}$ & - & - & - & 366 & 367 \\
\hline $\mathrm{Fe}-\mathrm{S}^{\mathrm{b}}$ & 384 & 382 & $390 \mathrm{sh}$ & 394 & 395 \\
\hline $\mathrm{Fe}-\mathrm{S}^{\mathrm{b}}$ & 402 & 400 & 404 & - & - \\
\hline $\mathrm{Fe}-\mathrm{S}^{\mathrm{b}}$ & 424 & $424 w$ & 426 & 428 & 426 \\
\hline
\end{tabular}

a $\mathrm{pH} 7.3$.

b Superscript $t$ indicates a terminal ligand and superscript $b$ indicates a bridging ligand. ${ }^{i}$ sh indicates the presence of a shoulder, $w$ signifies a weak Raman line. TRP and PDO data from this work; SFD and PUF data from Ref. 19.

Rieske protein are complicated by the fact that the $\mathrm{Fe}-\mathrm{S}^{\mathrm{t}}-\mathrm{C}$ and cysteine $\mathrm{S}^{\mathrm{t}}-\mathrm{C}-\mathrm{C}$ angle bending vibrations are expected in the region of observation, and these may mix with vibrations of the $\left[\mathrm{Fe}_{2} \mathrm{~S}_{2}^{\mathrm{b}}\right] \mathbf{S}^{\mathrm{t}}(\mathrm{Cys})_{4}$ core. We demonstrated this effect in studies of blue copper proteins, which showed that internal ligand deformations can have a substantial effect on the RR spectra of the chromophore [30]. This was subsequently confirmed for the particular case of $\mathrm{Fe} / \mathrm{S}$ proteins by Han et al. [26] who demonstrated interaction between the $\mathrm{S}^{\mathrm{t}}-\mathrm{C}-\mathrm{C}$ bending motion and two $\mathrm{Fe}-\mathrm{S}^{\mathrm{t}}$ stretching modes, as well as substantial coupling between terminal and bridging $\mathrm{Fe}-\mathrm{S}$ modes in $[2 \mathrm{Fe}-2 \mathrm{~S}]$ protein analogues. This mixing is dependent upon the $\mathrm{Fe}-\mathrm{S}^{\mathrm{t}}-\mathrm{CC}$ dihedral angle, which varies in the different $[2 \mathrm{Fe}-2 \mathrm{~S}]$ proteins. Additionally, hydrogen bonding interactions can have an appreciable effect on the frequencies of the Fe-S vibrations in different proteins [23].

As shown in Table I, ferredoxin RR spectra exhibit seven well documented RR lines. By contrast to the ferredoxin spectra, the RR spectra of TRP and PDO show at least ten peaks below $450 \mathrm{~cm}^{-1}$, depending on excitation wavelength (see Fig. 1). As discussed previously [17], the appearance of more peaks in the PDO and TRP spectra can be understood by comparing the symmetry of the $\left[\mathrm{Fe}_{2} \mathrm{~S}_{2}^{\mathrm{b}}\right] \mathrm{S}^{\mathrm{t}}(\mathrm{Cys})_{4}$ core to the structural

\footnotetext{
* It should be noted, however, that subtle differences were found in the spectra of these two ferredoxins in the presence of $\mathrm{D}_{2} \mathrm{O}$, probably due to different hydrogen bonding effects [22]. We assume nevertheless that the structures are fundamentally similar.
} 
options of the iron-sulfur-nitrogen clusters. In the centrosymmetric structures (point groups $\mathrm{D}_{2 \mathrm{~h}}$ and $\mathrm{C}_{2 \mathrm{~h}}$ ) possible for the $\left[\mathrm{Fe}_{2} \mathrm{~S}_{2}^{b}\right] \mathrm{S}^{\mathrm{t}} \mathrm{N}^{\mathrm{t}}$ core of the Rieske-type proteins (and discounting possible contributions from skeletal modes of the ligands) there are nine Raman active vibrations. Accordingly, with the peaks observed in the TRP and PDO spectra, the symmetry of the $\left[\mathrm{Fe}_{2} \mathrm{~S}_{2}^{\mathrm{b}}\right] \mathrm{S}^{\mathrm{t}}$ (Cys) ${ }_{2} \mathrm{~N}$ (His) ${ }_{2}$ cluster is likely not centrosymmetric. We therefore concluded [17] that the structure must be at most $C_{2 v}$ with either one nitrogen on both irons or both nitrogens on one iron. The latter structure is preferred, since the observed number of peaks can occur only if the iron-sulfur core experiences a major perturbation away from centrosymmetry such that formerly ungerade motions become Raman allowed; and, this structure is supported by Mössbauer studies of TRP [18].

Fig. 1 illustrates some of the strong similarities between the RR spectra of SFD, TRP, and PDO. In contrast to the established spectrum of various ferredoxins, TRP and PDO show additional peaks between 200 and $330 \mathrm{~cm}^{-1}$, some of which presumably possess substantial $\mathrm{Fe}$ (III)-N(His) character. TRP and PDO are expected to exhibit $\mathrm{Fe}$ (III)-N stretches in addition to the vibrations observed in the purely iron-sulfur proteins and these peaks are expected in the 200 to 300 $\mathrm{cm}^{-1}$ region (cf. Refs. 31-33).

In comparing the observed Raman peaks between 250 and $450 \mathrm{~cm}^{-1}$ (see Table I) with ferredoxins, additional peaks are clearly observed near 260 and 400 $\mathrm{cm}^{-1}$ for TRP and PDO. At least two more peaks are observed between 300 and $350 \mathrm{~cm}^{-1}$, but exact frequencies are difficult to assign because this region is unresolved. Indeed, some of the Raman peaks in TRP and PDO are weak and only definitively observed at certain excitation wavelengths. It should further be noted that comparisons to spectra of ferredoxins are difficult in the absence of isotope data. Below 200 $\mathrm{cm}^{-1}$ where angle deformations are expected, at least one additional peak is evident in TRP and PDO as compared to SFD (not shown here). Bending motions such as S-Fe-S and Fe-S-Fe are expected for SFD, while TRP and PDO should exhibit these deformations as well as motions involving the nitrogen ligands.

Overtone and combination modes have been observed in the $500-800 \mathrm{~cm}^{-1}$ region for several [2Fe-2S] ferredoxins $[20,22,25]$. However, no such lines are observed in the spectra of TRP and PDO (spectra not shown).

\section{Depolarization ratio measurements}

Depolarization ratios can provide information about the symmetry of the various vibrational modes. Spectra were recorded at low temperature $(74 \mathrm{~K})$ in a $1: 1$ ethylene glycol/water glass, and depolarization ratios measured for several RR peaks of SFD, TRP and
TABLE II

Resonance Raman frequencies $\left(\mathrm{cm}^{-1}\right)$ and depolarization ratios ${ }^{a}$ measured for TRP, PDO and SFD at pH 7.3

\begin{tabular}{llll}
\hline TRP & PDO & SFD $^{b}$ & SFD $^{c}$ \\
\hline $266 \backslash 0.49 \mathrm{p}$ & & $283 \backslash 0.48 \mathrm{p}$ & $285 \backslash 0.46 \mathrm{p}$ \\
$330 \backslash 0.36 \mathrm{p}$ & $334 \backslash 0.38 \mathrm{p}$ & $328 \backslash 0.48 \mathrm{p}$ & $330 \backslash 0.40 \mathrm{p}$ \\
& & $336 \backslash 0.57 \mathrm{p}$ or d & $340 \backslash 0.50 \mathrm{p}$ or d \\
$359 \backslash 0.58 \mathrm{p}$ or d & $354 \backslash 0.34 \mathrm{p}$ & & \\
& $372 \backslash 0.30 \mathrm{p}$ & $366 \backslash 0.55 \mathrm{p}$ or d & $369 \backslash 0.55 \mathrm{p}$ or d \\
$384 \backslash 0.38 \mathrm{p}$ & & $394 \backslash 0.48 \mathrm{p}$ & $397 \backslash 0.38 \mathrm{p}$ \\
$401 \backslash 0.33 \mathrm{p}$ & $404 \backslash 0.43 \mathrm{p}$ & & \\
$424 \backslash 0.18 \mathrm{p}$ & $426 \backslash 0.35 \mathrm{p}$ & & $428 \backslash 0.53 \mathrm{p}$ or d \\
\hline
\end{tabular}

${ }^{a}$ Data obtained in a glass of $1: 1$ ethylene glycol to water at $74 \mathrm{~K}$. p indicates polarized and $\mathrm{d}$ represents depolarized; estimated error is $\pm 20 \%$.

b This work.

${ }^{c}$ From Ref. 22.

PDO at $\mathrm{pH} 7.3$ (Table II). In agreement with the results of Meyer et al. [22], we find three and possibly five peaks in the spectrum of SFD to be polarized and therefore due to symmetric vibrations. The Raman peaks at 283,328 and $394 \mathrm{~cm}^{-1}$ are clearly polarized. In addition, the peaks at 336 and $366 \mathrm{~cm}^{-1}$, appear to be polarized, but this conclusion must be tempered somewhat due to experimental uncertainty in the intensity measurements. The remaining peaks are not of sufficient intensity to determine their depolarization ratios.

Depolarization ratio measurements of TRP and PDO indicate that at least five of the observed Raman peaks are polarized. In TRP the peaks at 266, 330, 384, 402 and $424 \mathrm{~cm}^{-1}$ are due to polarized vibrations. The Raman peak at $360 \mathrm{~cm}^{-1}$ may be polarized, while the remaining peaks are of insufficient intensity to obtain accurate measurements. The PDO peaks which are definitely polarized are located at $334,354,372,404$, and $426 \mathrm{~cm}^{-1}$. Depolarization ratios above about 0.3 for all modes provide clear indication that the core in TRP and PDO has an effective symmetry lower than the idealized maximum symmetry of $\mathrm{C}_{2 \mathrm{v}}$ (cf. Ref. 22).

\section{pH effects}

The [2Fe-2S] cluster of PDO appears to be structurally similar to those of the TRP, but there are some significant differences. As noted above, the midpoint potentials of PDO and related dioxygenases are typically less than $-100 \mathrm{mV}$, while the midpoint potentials of the clusters in Rieske proteins are above $100 \mathrm{mV}$. The potentials in the Rieske proteins are affected by a redox-linked protonation of the cluster wherein the oxidized form of the cluster reversibly loses a proton 
with $\mathrm{p} K_{\mathrm{a}} \approx 8$ (cf. Ref. 11 ). We previously reported that the relative $R R$ intensities and some frequencies in the spectrum of TRP appeared to be $\mathrm{pH}$-dependent [17]. These changes are not observed in spectra of PDO or SFD. To differentiate between the effect of $\mathrm{pH}$ on $\mathrm{RR}$ frequencies and on changes in resonance enhancement at different $\mathrm{pH}$ values in TRP, the RR spectra of TRP at $\mathrm{pH} 7.3$ and 10.1 were compared to that of PDO as a function of excitation wavelength (Figs. 2-5). The optical spectrum, certain RR frequencies, and the RR excitation profile of TRP at $\mathrm{pH} 10.1$ are markedly different from those of the protein at $\mathrm{pH}$ 7.3. Fig. 2 shows the optical spectra of TRP at $\mathrm{pH} 7.3$ and 10.1 along with the excitation profiles for the more intense
RR peaks. Figs. 3, 4 and 5 present the RR spectra of TRP at $\mathrm{pH} 7.3$, TRP at $\mathrm{pH} 10.1$ and PDO at $\mathrm{pH} 7.3$, respectively, as a function of excitation wavelength.

The TRP RR spectra reveal several changes upon raising the $\mathrm{pH}$ from 7.3 to 10.1 . The peak at $266 \mathrm{~cm}^{-1}$ at $\mathrm{pH} 7.3$ shifts at the higher $\mathrm{pH}$ to $274 \mathrm{~cm}^{-1}$. The very slight asymmetry of the $266 \mathrm{~cm}^{-1}$ peak at pH 7.3 may be due to the presence of a $274 \mathrm{~cm}^{-1}$ peak as a weak shoulder. A shoulder at $266 \mathrm{~cm}^{-1}$ is discernable on the $274 \mathrm{~cm}^{-1}$ peak in the $\mathrm{pH} 10.1$ spectrum, suggesting the presence of an additional peak near $270 \mathrm{~cm}^{-1}$. Excitation profile data (Figs. 3 and 4) indicate that this intensity change is not a result of differing resonance enhancement arising from changes in the absorption

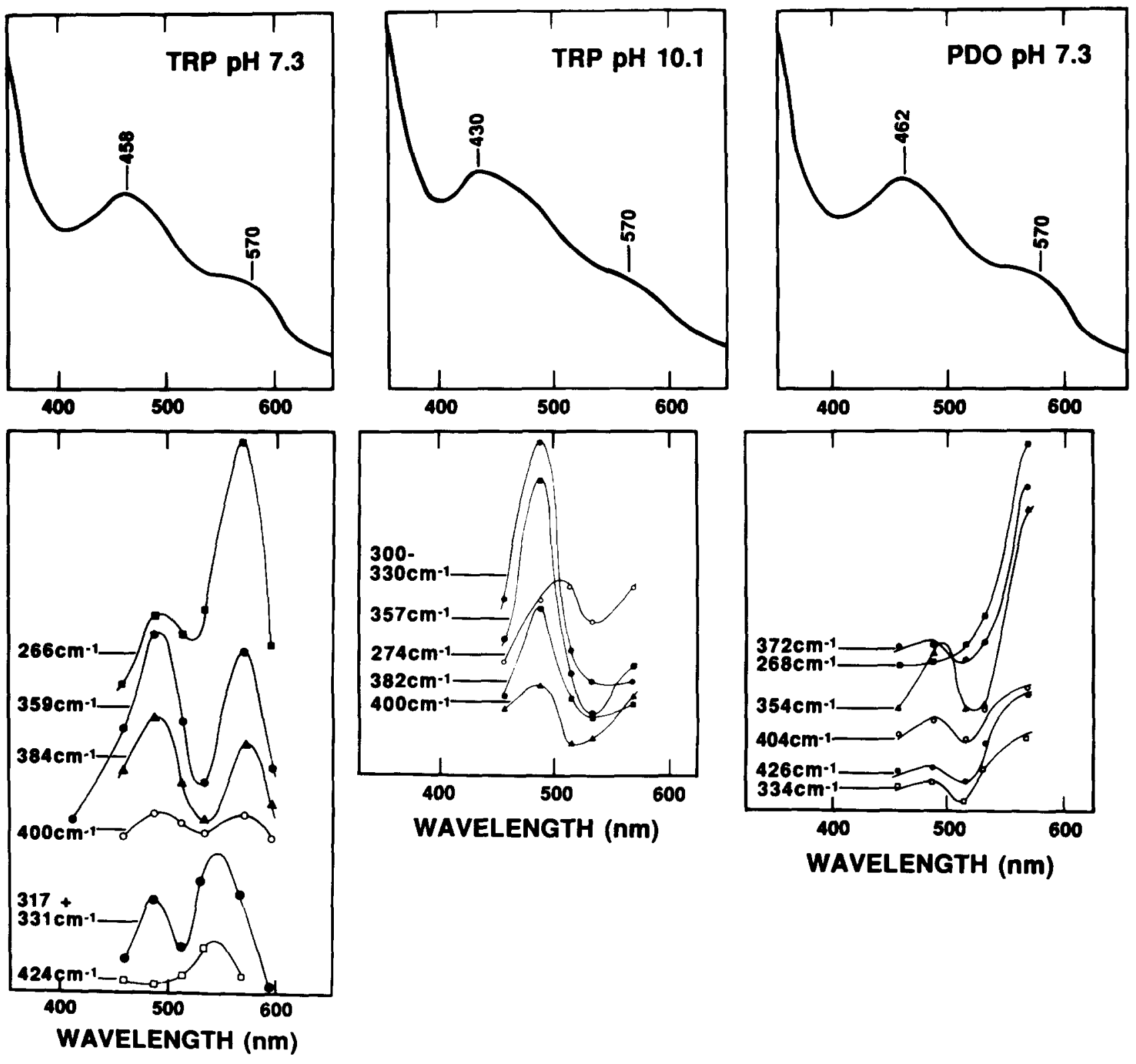

Fig. 2. The optical spectra (top panels) and Raman excitation profiles for individual Raman modes (bottom panels) are presented for PDO and TRP at $\mathrm{pH} 7.3$ and TRP at $\mathrm{pH} 10.1$. The intensities for the excitation profile are relative to the ice peak at $230 \mathrm{~cm}^{-1}$. The actual spectra are displayed in Figs. 3, 4 and 5. 


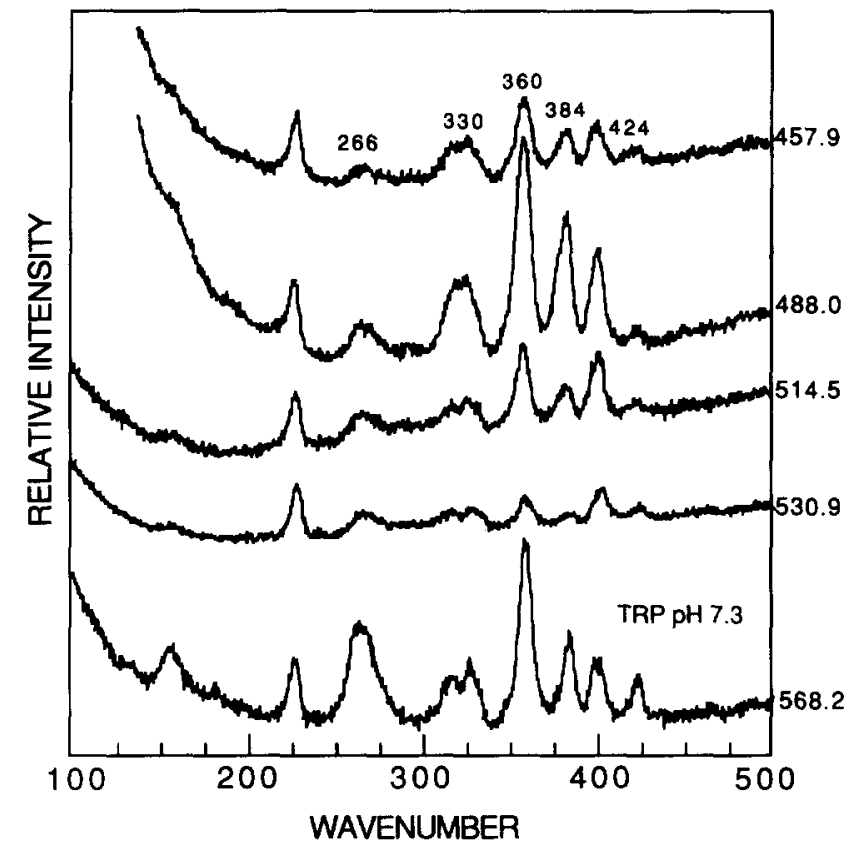

Fig. 3. RR spectra of oxidized TRP at pH 7.3 as a function of laser excitation wavelength. The spectra were obtained with the laser wavelength noted to the right of the spectrum with the conditions as in Fig. 1.

spectrum. The $274-\mathrm{cm}^{-1}$ peak gains intensity at $\mathrm{pH}$ 10.1 with a concomitant loss in intensity at $266-\mathrm{cm}^{-1}$; this is independent of excitation wavelength. We sug-

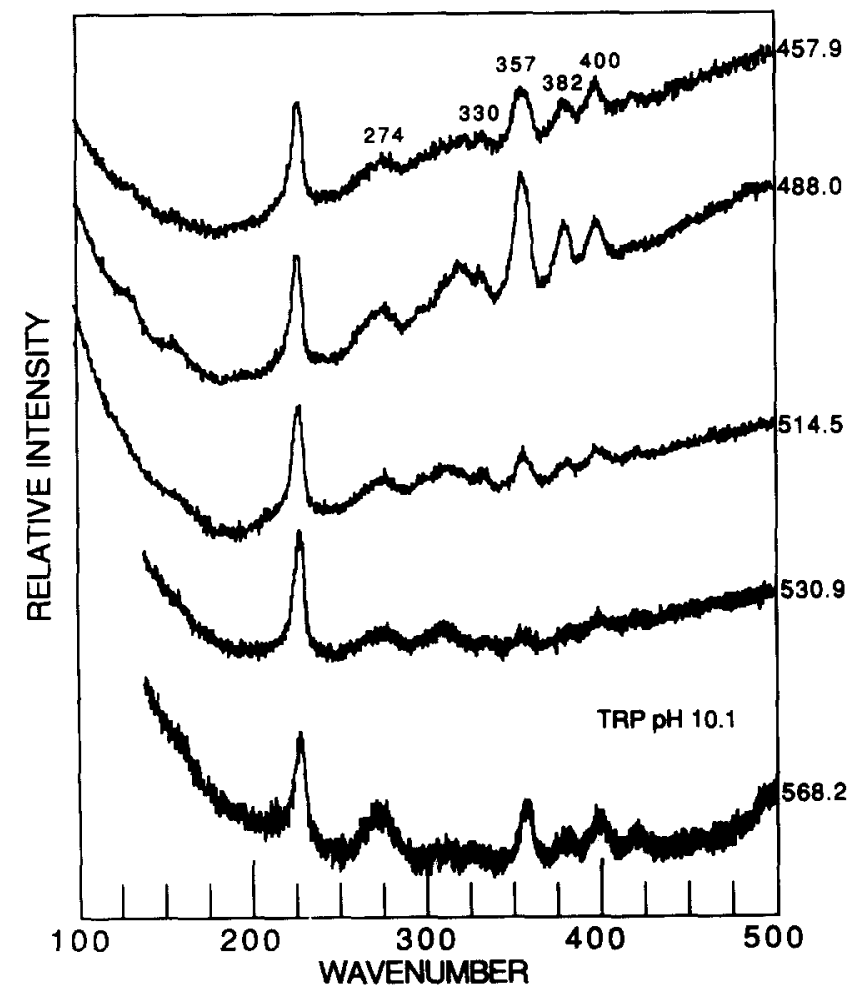

Fig. 4. RR spectra of TRP at $\mathrm{pH} 10.1$ at various excitation wavelengths. The conditions are as in Fig. 1 and the laser wavelength is to the right of the spectrum.

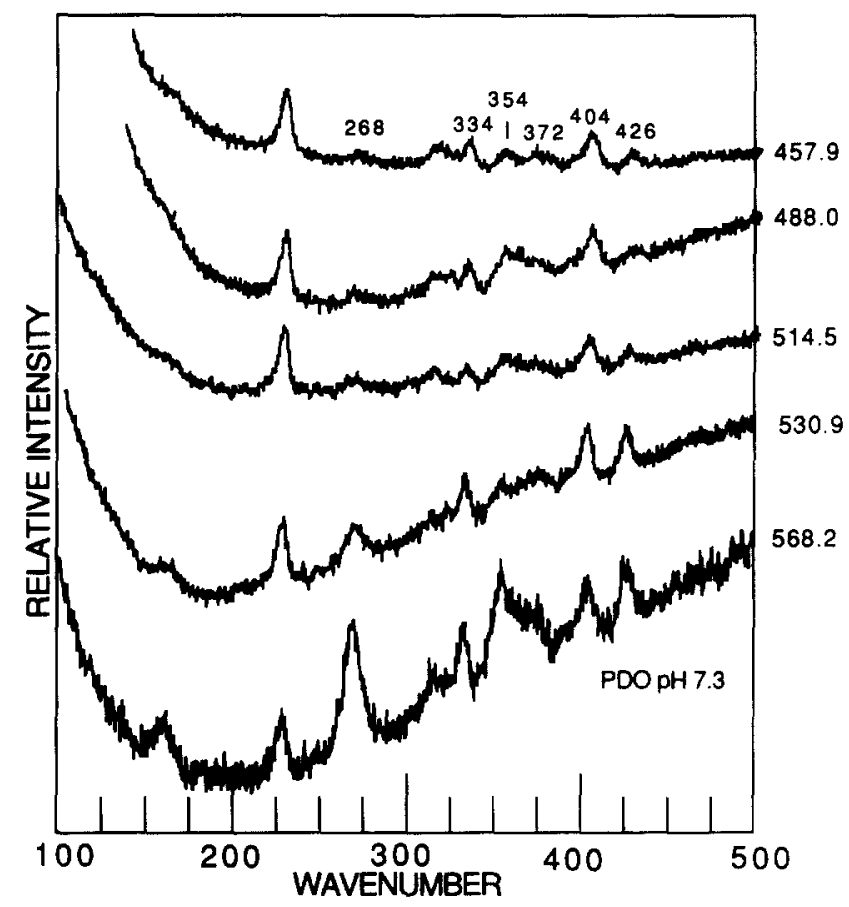

Fig. 5. RR spectra of oxidized $\mathrm{PDO}$ at $\mathrm{pH} 7.3$ as a function of excitation wavelength; conditions as in Fig. 1 with the wavelength listed to the right of the spectrum.

gest that these peaks are predominately $\mathrm{Fe}$ (III)-N(His) in character, and exhibit the observed $\mathrm{pH}$-dependent shift because of protonation and deprotonation of one of the Fe-bound histidine imidazoles (Ref. 34; cf. Ref. 11 and below). The small shift in vibrational frequency is consistent with the protonated form possessing a hydrogen bond. For example, the Fe(II)-N(His) frequency in cytochrome $c$ peroxidase consists of components at $233 \mathrm{~cm}^{-1}$ and $246 \mathrm{~cm}^{-1}$ assigned to hydrogen bonded and deprotonated imidazole, respectively, while, in the non-hydrogen bonded form, the Fe(II)$\mathrm{N}($ His $)$ is observed at $205 \mathrm{~cm}^{-1}$ [35]. Additionally, a Raman band appears at $300 \mathrm{~cm}^{-1}$ in the TRP spectrum at $\mathrm{pH} 10.1$. This peak is likely shifted from the $300-320 \mathrm{~cm}^{-1}$ region, although it is difficult to quantify this shift because this region of the spectrum contains numerous overlapping peaks. In idealized $\mathrm{C}_{2 \mathrm{v}}$ symmetry for the $\left[\mathrm{S}_{2}^{\mathrm{t}} \mathrm{FeS}{ }_{2}^{\mathrm{b}} \mathrm{Fe}[\mathrm{N}(\mathrm{His})]_{2}^{t}\right]$ cluster, two $\mathrm{Fe}$ $\mathrm{N}^{\mathrm{t}}$ stretches are Raman active, making it likely that the band at $300 \mathrm{~cm}^{-1}$ in the $\mathrm{pH} 10.1$ TRP sample is due to an $\mathrm{Fe}-\mathrm{N}^{t}$ stretch.

The structural change need not be localized to one or two vibrational modes, nor will the $\mathrm{pH}$ dependence necessarily follow a simple equilibrium. Indeed, RR peaks other than the $266-274 \mathrm{~cm}^{-1}$ pair undergo frequency shifts with changing $\mathrm{pH}$. The peaks at 402,384 and $360 \mathrm{~cm}^{-1}$ shift to 400,382 and $357 \mathrm{~cm}^{-1}$, respectively, upon raising the $\mathrm{pH}$. These peaks are probably $\mathrm{Fe}-\mathrm{S}$ vibrations, the frequency shifts reflecting the effect of deprotonation upon Fe-S bonding. This slight 
weakening of the Fe-S bonds is either caused directly by the strengthening of the $\mathrm{Fe}-\mathrm{N}$ bond upon deprotonation or by a protein conformational change which may accompany the protonation/deprotonation reaction. There may be additional changes in the 300 to $350 \mathrm{~cm}^{-1}$ range, but these are difficult to gauge because of the numerous overlapping Raman lines. Another change observed at high $\mathrm{pH}$ is the loss of intensity of the RR peak at $424 \mathrm{~cm}^{-1}$. At pH 10.1 the 424 $\mathrm{cm}^{-1}$ peak appears very weak with exciting wavelengths between 457.9 and $530.9 \mathrm{~nm}$, but it gains intensity with $568.2 \mathrm{~nm}$ excitation (see Fig. 4). Accordingly, the intensity change in this peak can be ascribed to changes in resonance enhancement (see below).

It has previously been suggested that ionization of one of the coordinated histidine imidazole groups is responsible for the $\mathrm{pH}$ dependence of $E_{\mathrm{m}}$ observed with the respiratory-type proteins $[11,16]$. This is reasonable because coordination to a metal is known to strongly shift the $\mathrm{p} K_{\mathrm{a}}$ of the imidazole/imidazolate equilibrium toward lower $\mathrm{pH}$ (from $\mathrm{p} K_{\mathrm{a}}=14.2$ ) (cf. Ref. 36 and references therein). Moreover, the present RR data are generally consistent with such an ionization occurring between $\mathrm{pH} 7.3$ and 10.1. The most likely explanation for the fact that the two bands (266 $\mathrm{cm}^{-1}$ dominant at $\mathrm{pH} 7.3$ and $274 \mathrm{~cm}^{-1}$ dominant at $\mathrm{pH} 10.1)$ are both observed at the $\mathrm{pH}$ extremes is that only one of the two imidazole rings ionizes at high $\mathrm{pH}$. That is, the shoulder on the high-wavenumber side of the $266 \mathrm{~cm}^{-1}$ peak is likely caused by a small amount of ionization at $\mathrm{pH} 7.3$. At $\mathrm{pH} 10.1$, the shoulder near $266 \mathrm{~cm}^{-1}$ represents the mode for the second imidazole ring which does not ionize, much the same as PDO. Previous measurements suggested $\mathrm{p} K_{\mathrm{a}} \approx 8$ [15], but unpublished work indicates that this value may depend on the preparation of TRP * Because PDO appears to be insensitive to changes in $\mathrm{pH}$, it would seem that the coordination effect by itself is not adequate to shift the ionization of the coordinated imidazole into our working $\mathrm{pH}$ range. To account for this difference in behavior between the two proteins, we speculate that an additional aid to ionization must exist in the respiratory-type proteins, namely a closely disposed, positively charged amino acid residue that could form a hydrogen bond with the coordinated imidazolate. The presence of a nearby positive charge could have the additional effect of stabilizing the reduced form, thereby raising the mid-point potential.

\section{Wavelength dependence}

The visible absorption spectra of the Rieske-type proteins contain numerous overlapping, broad bands

\footnotetext{
* Unpublished circular dichroism spectra obtained in the $\mathrm{pH}$ range 7 to 10 suggest a $\mathrm{p} K_{\mathrm{a}}$ of about 9 (Kuila, D., Edmondson, S. and Fee, J.A. unpublished data).
}

due to ligand-to-metal charge-transfer transitions. The optical spectra of TRP and PDO at pH 7.3 (Fig. 2) exhibit absorbance maxima near 570 and $460 \mathrm{~nm}$, while the spectrum of TRP at $\mathrm{pH} 10.1$ demonstrates some differences. The excitation profiles of the stronger RR peaks are shown in the lower panel in Fig. 2. The ice band at $230 \mathrm{~cm}^{-1}$ served as the internal intensity standard.

Yachandra et al. [20] noted a different degree of resonance enhancement for bridging versus terminal sulfur modes of SFD, and Willis and Loehr [37] also observed this type of behavior for [2Fe-2S] centers from milk xanthine oxidase. No differential enhancement of $\mathrm{Fe}-\mathrm{S}^{\mathrm{t}}$ and $\mathrm{Fe}-\mathrm{S}^{\mathrm{b}}$ modes is evident in the spectra of TRP and PDO. However, the Raman peak at $266 \mathrm{~cm}^{-1}$ in TRP at pH $7.3\left(274 \mathrm{~cm}^{-1}\right.$ at pH 10.1$)$, which we assign as substantially $\mathrm{Fe}$ (III)-N(His) in nature, shows a unique excitation profile when compared to the other Raman lines (Fig. 2). It is also significant that the $268-\mathrm{cm}^{-1}$ peak in PDO spectra is the only Raman line which shows little wavelength dependence between 450 and $500 \mathrm{~nm}$. This observation suggests the possibility that the $268-\mathrm{cm}^{-1}$ peak, like the mode near $270 \mathrm{~cm}^{-1}$ in TRP, is due to a $\mathrm{Fe}$ (III)-N(His) stretch. The excitation profiles of TRP and PDO differ significantly from what is expected considering the similarity of their absorption spectra. For example, the excitation profile of adrenodoxin [19] roughly tracks the absorption spectrum, with greater enhancement occurring with shorter excitation wavelength. In contrast, TRP and PDO demonstrate remarkable enhancements at longer wavelengths. The TRP and PDO profiles show a maximum near $490 \mathrm{~nm}$ and another at longer wavelength ( $>$ about $550 \mathrm{~nm}$ ). Interference effects from the different charge transfer transitions and anti-resonance effects may be important in causing these unique profiles.

\section{Reduced TRP and PDO}

RR spectra of reduced ferredoxins have to our knowledge, not previously been reported (cf. Ref. 38). Several papers $[19,23,25]$ have, however, reported spectra of reduced adrenodoxin and 'red paramagnetic protein' (RPP) from Clostridrium pasteurianum. The data were interpreted as showing that the added electron is localized on one end of the $\left[\mathrm{Fe}_{2} \mathrm{~S}_{2}^{\mathrm{b}}\right] \mathrm{S}^{\mathrm{t}}(\mathrm{Cys})_{4}$ unit such that the core is [ $\mathrm{Fe}(\mathrm{II}) \mathrm{S}_{2}^{\mathrm{b}} \mathrm{Fe}$ (III)]. Upon reduction, the frequencies of bridging modes shift to lower frequency by $15-24 \mathrm{~cm}^{-1}$ due to a weakening of the bridge bonds to the $\mathrm{Fe}$ (II) side of the cluster. In adrenodoxin, the assignments of the $\mathrm{Fe}-\mathrm{S}^{\mathrm{b}}$ vibrations were confirmed by frequency shifts upon isotopic substitution of the bridging $S$ atoms [19].

Fig. 6 presents the RR spectra of reduced PDO and TRP. As in adrenodoxin and RPP, the peaks believed 


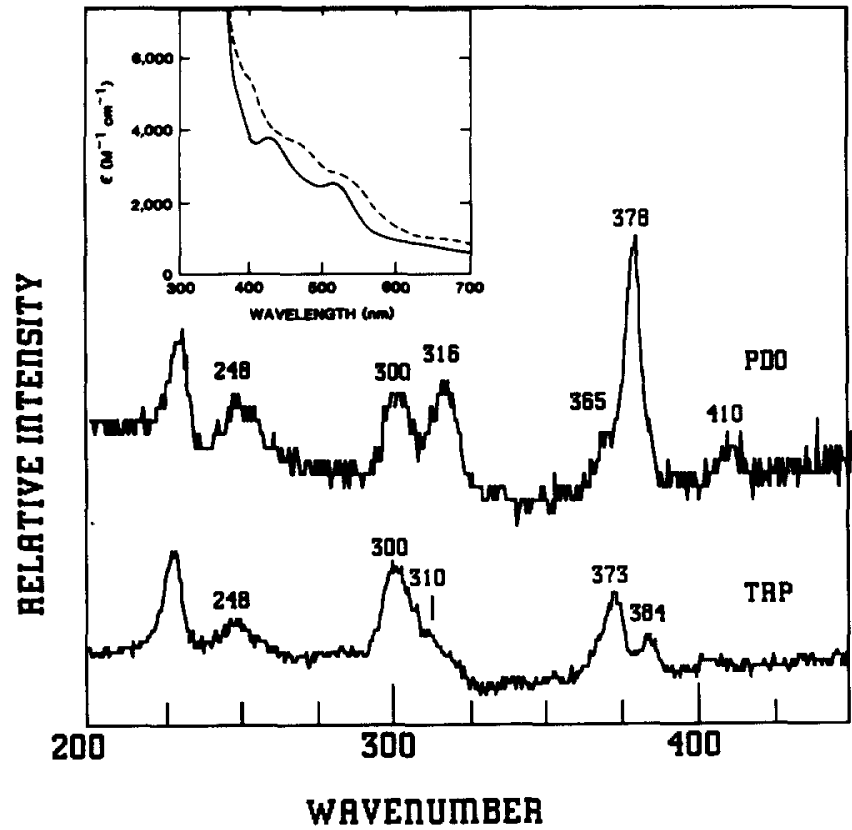

Fig. 6. RR spectra of dithionite-reduced PDO (top trace) and TRP (bottom trace) between 200 and $450 \mathrm{~cm}^{-1}$. Both spectra were recorded at $74 \mathrm{~K}$ using $514.5 \mathrm{~nm}$ excitation and the instrumental conditions noted in Fig. 1. Because the $S / N$ was significantly lower (cf. Ref. 38), these spectra have been subjected to a smoothing routine. The inset provides the optical spectra of reduced SFD (dashed) and TRP (solid) (cf. Ref. 11); the optical spectra of reduced TRP and PDO are indistinguishable.

to be primarily $\mathrm{Fe}-\mathrm{S}^{\mathrm{b}}$ stretching modes exhibit a significant shift to lower frequency. In TRP, the peaks in the oxidized protein at 384 and $402 \mathrm{~cm}^{-1}$ ascribed to $\mathrm{Fe}-\mathrm{S}^{\mathrm{b}}$ motions shift to 373 and $384 \mathrm{~cm}^{-1}$ in the reduced form. Likewise, the $404 \mathrm{~cm}^{-1}$ band in oxidized PDO and the accompanying shoulder at $390 \mathrm{~cm}^{-1}$ shift to 378 and $365 \mathrm{~cm}^{-1}$. The other Raman peaks in the oxidized proteins attributed to $\mathrm{Fe}_{2} \mathrm{~S}_{2}^{\mathrm{b}}$ stretches are at 426 (PDO) and $424 \mathrm{~cm}^{-1}$ (TRP) and shift to 410 and $405 \mathrm{~cm}^{-1}$, respectively, in the reduced spectra.

There are three additional peaks in the reduced protein spectra of PDO and TRP between 200 and 320 $\mathrm{cm}^{-1}$ which are similar to those reported for adrenodoxin and RPP. A straightforward explanation for this close similarity for $\mathrm{Fe} / \mathrm{S}$ and $\mathrm{Fe} / \mathrm{S} / \mathrm{N}$ clusters in the reduced state is that the observed peaks in these spectra arise from either $\mathrm{Fe}-\mathrm{S}^{\mathrm{b}}$ or $\mathrm{Fe}-\mathrm{S}^{\mathrm{t}}$ modes of the $\mathrm{Fe}(I I I)$ side of the cluster. It appears that in the RR spectra of the reduced proteins, the $\mathrm{Fe}$ (III)-S vibrations are selectively enhanced over the $\mathrm{Fe}$ (II)-S (or $\mathrm{N}$ ) modes, which are not observed in either the $\mathrm{Fe}-\mathrm{S}$ or the $\mathrm{Fe}-\mathrm{S}-\mathrm{N}$ clusters. The foregoing suggests that the electron in reduced TRP and PDO resides at the Fe atom bound by the two imidazole nitrogens from the histidine residues.

\section{Conclusions}

RR spectra have been assigned for a class of [ $2 \mathrm{Fe}-2 \mathrm{~S}]$ proteins that contain histidine-imidazole in addition to sulfur ligands. The Fe-St and Fe-S $\mathrm{S}^{\mathrm{b}}$ modes in TRP and PDO have been identified by comparison with the well-established spectrum of SFD. These assignments are verified with the spectra of reduced TRP and PDO as the $\mathrm{Fe}-\mathrm{S}^{\mathrm{b}}$ modes exhibit the expected shift to lower frequency upon reduction. Excitation profile data demonstrate that the $\mathrm{Fe}-\mathrm{N}$ modes are enhanced in a different manner than the $\mathrm{Fe}-\mathrm{S}^{\mathrm{t}}$ or $\mathrm{Fe}-\mathrm{S}^{\mathrm{b}}$ modes.

The Raman spectrum of TRP, but not that of PDO, is sensitive to $\mathrm{pH}$. Varying the $\mathrm{pH}$ permitted the assignment of a RR band near $270 \mathrm{~cm}^{-1}$ to an Fe(III)$\mathrm{N}$ (His) stretch. It is suggested that this band consists of two components arising from populations having protonated-hydrogen-bonded imidazole and deprotonatedhydrogen-bonded imidazolate. This protonation/ deprotonation equilibrium of an $\mathrm{Fe} / \mathrm{S}$ coordinated imidazole ring is proposed to be responsible for the $\mathrm{pH}$ dependence of $E_{\mathrm{m}}$, and a simple structural model involving the formation of an $\mathrm{Fe}$ bound imidazolate group near a positively charged residue is proposed to distinguish the $\mathrm{pH}$-dependent behavior of TRP and PDO.

Raman spectra of reduced TRP and PDO are very similar to those published for adrenodoxin and RPP $[19,23,25]$. This result demonstrates that only Fe(III)-S modes are observed and is consistent with the idea that in Rieske-type proteins the electron resides on the iron atom bound by the histidine residues. The reduced protein spectra thereby supply additional evidence for the proposed structure of the $\left[\mathrm{Fe}_{2} \mathrm{~S}_{2}^{\mathrm{b}}\right] \mathbf{S}^{\mathrm{t}}(\mathrm{Cys})_{2} \mathrm{~N}(\mathrm{His})_{2}$ unit where the two histidine residues are bound to the same iron atom.

\section{Acknowledgements}

This work was supported by U.S. Public Health Service NIH Grants GM35342 to J.A.F., DK36263 to W.H.W and GM20877 to D.P.B. The work performed at Los Alamos National Laboratory was carried out under the auspices of the U.S. Department of Energy.

\section{References}

1 Beinert, H. (1990) FASEB J. 4, 2483-2491.

2 Spiro, T.G. (ed.) (1982) Iron-Sulfur Proteins, Wiley-Interscience, New York.

3 Matsubara, H., Katsube, Y. and Wada, K. (eds.) (1987) Iron-Sulfur Protein Research, Springer, Berlin.

4 Fukuyama, K., Hase, T., Matsumoto, S., Tsukihara, T., Katsube, Y., Tanaka, N., Kakudo, M., Wada, K. and Matsubara, H. (1980) Nature 286, 522-524.

5 Rypniewski, W.R., Breiter, D.R., Benning, M.W., Wesenberg, G. Oh, B.-H., Markley, J.L., Rayment, I. and Holden, H. (1991) Biochemistry 30, 4126-4131. 
6 Bearwood, P. and Gibson, J.F. (1983) J. Chem. Soc. Dalton Trans., 737-748.

7 Sands, R.H. and Dunham, W.R. (1975) Q. Rev. Biophys. 7, 443-504.

8 Estabrook, R.W., Simpson, K., Mason, J.I., Baron, J., Taylor, W.E., Simpson, E.R., Purvis, J. and McCarthy, J. (1973) in Iron-Sulfur Proteins (Lovenberg, W. ed.), Vol. I, Ch. 8, pp. 193-223, Academic Press, New York.

9 Gunsalus, I.C. and Lipscomb, J.D. (1973) in Iron-Sulfur Proteins (Lovenberg, W., ed.), Vol. I, Ch. 6, pp. 151-171, Academic Press, New York.

10 Flint, D.H. and Emptage, M.H. (1988) J. Biol. Chem. 263, 35583564.

11 Fee, J.A., Kuila, D., Mather, M. and Yoshida, T. (1986) Biochim. Biophys. Acta 853, 153-185.

12 Batie, C.J., Ballou, D.P. and Correll, C.C. (1991) in Chemistry and Biochemistry of Flavoproteins, (Müller, F., ed.), Vol. 3, Ch. 18, CRC Press, Boca Raton.

13 Gurbiel, R.J., Batie, C.J., Sivaraja, M., True, A.E., Fee, J.A., Hoffman, B.M. and Ballou, D.P. (1989) Biochemistry 28, 48614871 .

14 Britt, R.D., Sauer, K., Klein, M.P., Knaff, D.B., Kriauciunas, A., Yu, C.-A., Yu, L. and Malkin, R. (1991) Biochemistry 30, 18921901.

15 Gurbiel, R.J., Ohnishi, T., Robertson, D.E., Daldal, F. and Hoffman, B.M. (1991) Biochemistry, 30, 11579-11584.

16 Kuila, D. and Fee, J.A. (1986) J. Biol. Chem. 261, 2768-2771.

17 Kuila, D., Fee, J.A., Schoonover, J.R., Woodruff, W.H., Batie, C.J. and Ballou, D.P. (1987) J. Am. Chem. Soc. 109, 1559-1561.

18 Fee, J.A., Findling, K.L., Yoshida, T., Hille, R., Tarr, G.E., Hearshen, D.O., Dunham, W.R., Day, E.P., Kent, T.A. and Münck, E. (1984) J. Biol. Chem. 259, 124-133.

19 Han, S., Czernuszewicz, R.S., Kimura, T., Adams, M.W.W. and Spiro, T.G. (1989) J. Am. Chem. Soc. 111, 3505-3511.

20 Yachandra, V.K., Hare, J., Gewirth, A., Czernuszewicz, R.S, Kimura, T., Holm, R.H. and Spiro, T.G. (1983) J. Am. Chem. Soc. 105, 6462-6468.

21 Meyer, J., Moulis, J.-M. and Lutz, M. (1984) Biochem. Biophys. Res. Commun. 119, 828-835.
22 Meyer, J., Moulis, J.-M. and Lutz, M. (1986) Biochim. Biophys. Acta. 873, 108-118.

23 Mino, Y., Loehr, T.M., Wada, K., Matsubara, H. and SandersLoehr, J. (1987) Biochemistry 26, 8059-8065.

24 Spiro, T.G., Czernuszewicz, R.S. and Han, S. (1988) in Biological Applications of Raman Spectroscopy (Spiro, T.G. ed.), Vol. III, Ch. 12, pp. 523-553, Wiley \& Sons, New York.

25 Yachandra, V.K., Hare, J., Gewirth, A., Czernuszewicz, R.S., Kimura, T., Holm, R.H. and Spiro, T.G. (1983) J. Am. Chem. Soc. 105, 6462-6468.

26 Han, S., Czernuszewicz, R.S. and Spiro, T.G. (1989) J. Am. Chem. Soc. 111, 3496-3504.

27 Bearwood, P. and Gibson, J.F. (1984) J. Chem. Soc. Dalton Trans. 1507-1516.

28 Petering, D.H. and Palmer, G. (1970) Arch. Biochem. Biophys. 141, 456-464.

29 Batie, C., LaHaie, E. and Ballou, D.P. (1987) J. Biol. Chem. 262, 1510-1518.

30 Blair, D.F., Campbell, G.W., Schoonover, J.R., Chan, S.I., Gray, H.B., Malmstrom, B.G., Pecht, I., Swanson, B.I., Woodruff, W.H., Cho, W.K., English, A.M., Fry, H.A., Lum, V. and Norton, K.A. (1985) J. Am. Chem. Soc. 107, 5755-5766.

31 Kurtz, D.M., Shriver, D.F. and Klotz, I.M. (1977) Coord. Chem. Rev. 24, 145-178.

32 Felton, R.H., Barrow, W.L., May, S.W., Sowell, A.L., Goel, S., Bunker, G and Stern, E.A. (1982) J. Am. Chem. Soc. 104, 6132-6134.

33 Walters, M.A. ad Spiro, T.G. (1983) Inorg. Chem. 22, 4014-4017.

34 Kitagawa, T. (1988) in Biological Applications of Raman Spectroscopy (Spiro, T.G., (ed.), Vol. III, Ch. 3, pp. 97-131, Wiley \& Sons, New York.

35 Smulevich, G., Mauro, J.M., Fishel, L.A., English, A.M., Kraut, J. and Spiro, T.G. (1988) Biochemistry 27, 5477-5485.

36 Winter, J.A., Caruso, D. and Shepard, R.E. (1988) Inorg. Chem. 27, 1086-1089.

37 Willis, L.J. and Loehr, T.M. (1985) Biochemistry 24, 2768-2772.

38 Macor, K.A., Czernuszewicz, R.S., Adams, M.W.W. and Spiro, T.G. (1987) J. Biol. Chem. 262, 9945-9947. 